\title{
Deep Geoelectrical Structure of the Central and Western Ukraine
}

\author{
Igor M. LOGVINOV \\ Institute of Geophysics, National Academy of Sciences of Ukraine, Kiev, Ukraine \\ e-mail: anna_log@ukr.net
}

\begin{abstract}
The results of deep induction sounding in Ukraine made in the twenty-first century with the participation of the author have been summarized, including also a number of data obtained in the previous decades. The apparent resistivity and magnetic transfer function on the territories of western Ukraine and eastern Poland have been analyzed. The articulation of these data with the regional magnetic variation soundings allowed taking into account the influence of a static shift of areal interpretation of magnetotelluric resistivity results, which increased the reliability of interpretation. The analysis of induction sounding performed with 1D, 2D, and 3D inversions of magnetic transfer functions allowed localizing the crustal anomalies. The results are discussed.
\end{abstract}

Key words: crust and mantle conductivity, East Carpathians, East European Plate.

\section{INTRODUCTION}

Geoelectric survey in Ukraine is actively underway since the 1970s. The main results made in the twentieth century were summarized by Rokityansky (1982), Bondarenko et al. (1972), Rokityansky et al. (1976), Dyakonova et al. (1986). The results of most of these studies were obtained from interpretation of thousands of magnetotelluric sounding (MTS) in the period range from 0.1 to $900 \mathrm{~s}$ made by industrial organizations of Ukraine (Ingerov et al. 
1999). Results of regional soundings of the mantle down to a depth of about $1000 \mathrm{~km}$ have been relatively recently obtained, using data from three geomagnetic observatories of Ukraine.

The basis for this work was the geoelectric study conducted in the past 15 years, with a number of magnetotelluric stations (Jankowski et al. 1984, Rakhlin et al. 2005) of the Institute of Geophysics of the National Academy of Sciences of Ukraine (IGF NANU). In addition, observations were carried out in the framework of two international projects: Central Europe Mantle geoElectrical Structure (CEMES), which was initiated by the Institute of Geophysics (IGF) of the Polish Academy of Sciences in 2001 (Semenov et al. 2008) and joint Polish-Ukrainian observations made in 2006-2007 in Poland and Ukraine. Additionally, this work includes part of the short period MTS results obtained by exploration organizations (Ingerov et al. 1999). Results of MTS with periods of more than 40 minutes were considered as deep MT soundings (DMTS) and analyzed together with the results of the regional magnetovariation soundings (MVS).

The area of research covers the south-western edge of the East European Platform (EEP) and the eastern part of the Carpathians (Fig. 1). Interpretation was carried out using 1D, 2D, and quasi-3D inversions. Studies in separate sub-regions were published by Gordienko et al. (2005, 2006, 2011, 2012). The paper summarizes the results of all deep geoelectric structures in the Western and Central Ukraine.

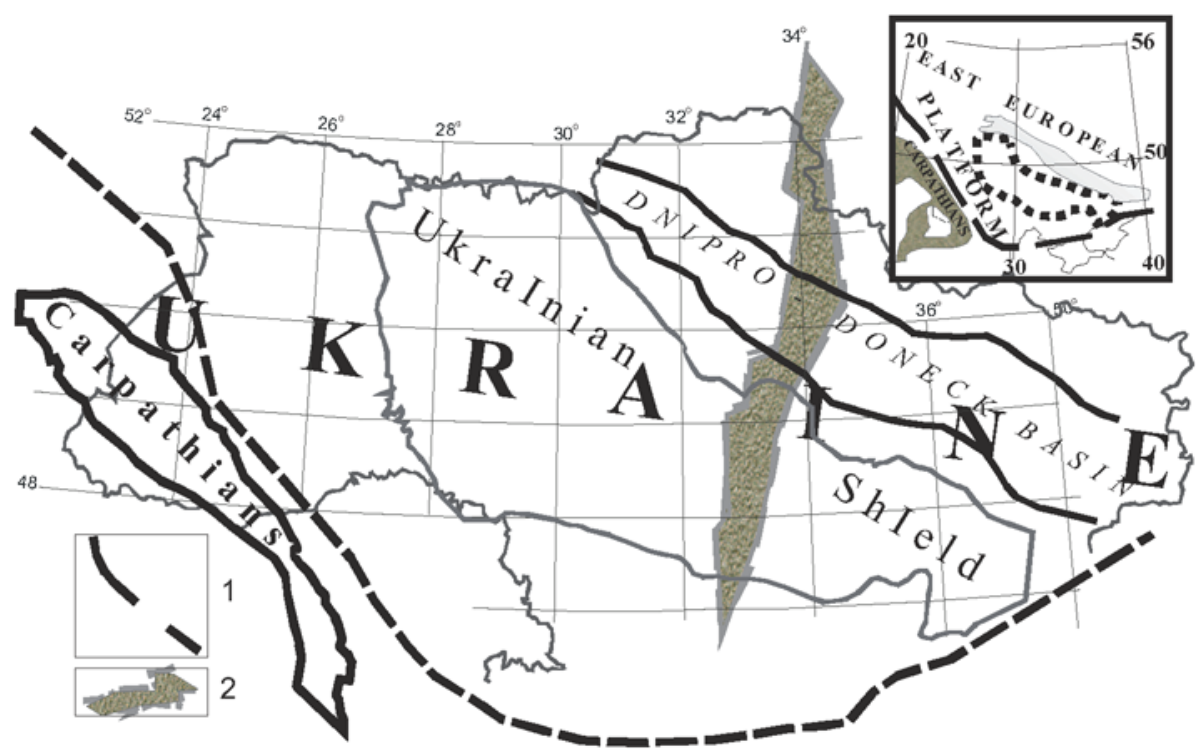

Fig. 1. Major tectonic units of the EEP and Carpathian: 1 - the EEP border, 2 - the Ingulets-Krivoy Rog-Krupetsk suture zone. 


\section{DATA AND PROCESSING}

Observations over the last 15 years consisted of digital measurements at about 200 sites across Ukraine and Poland made in the frames of PolishUkrainian cooperation. In addition, the data obtained in the frames of the international project PREPAN'95 were used (Ádám et al. 1997).

Recordings of magnetotelluric (MT) fields on photographic paper obtained by IGF NANU were digitized and processed (Gordienko et al. 2005). The impedance and magnetic transfer function data as well as MTS responses obtained by industrial organizations of Ukraine (calculated only in the directions of measurement lines oriented along magnetic meridians and parallels) formed the study database. The DMTS sites (with periods $>0.7 \mathrm{~h}$ ) and MTS profiles (with 15-30 sites at each) are shown in Fig. 2. The ultradeep regional induction soundings were made in two geomagnetic observatories, Kiev and Lviv (Semenov et al. 1998). Apparent resistivities estimated by the MTS method in two directions were further expanded with scalar apparent resistivities given by the MVS method at longer periods, reaching 11 years. This approach allows correcting shift effects in the MTS data, increasing the reliability of the analysis.

In addition, the three-month observations of the magnetic field in three sites located at $200-\mathrm{km}$ distances from each other at the Ukrainian Shield were carried out. The resulting transfer functions in the period range from $10^{4}$ to $10^{5} \mathrm{~s}$ were estimated under the assumption that the external magnetic field is represented by a specific plane wave having non-zero vertical magnetic component $B_{z}(t)$ at long periods. In such a case, the generalized MVS

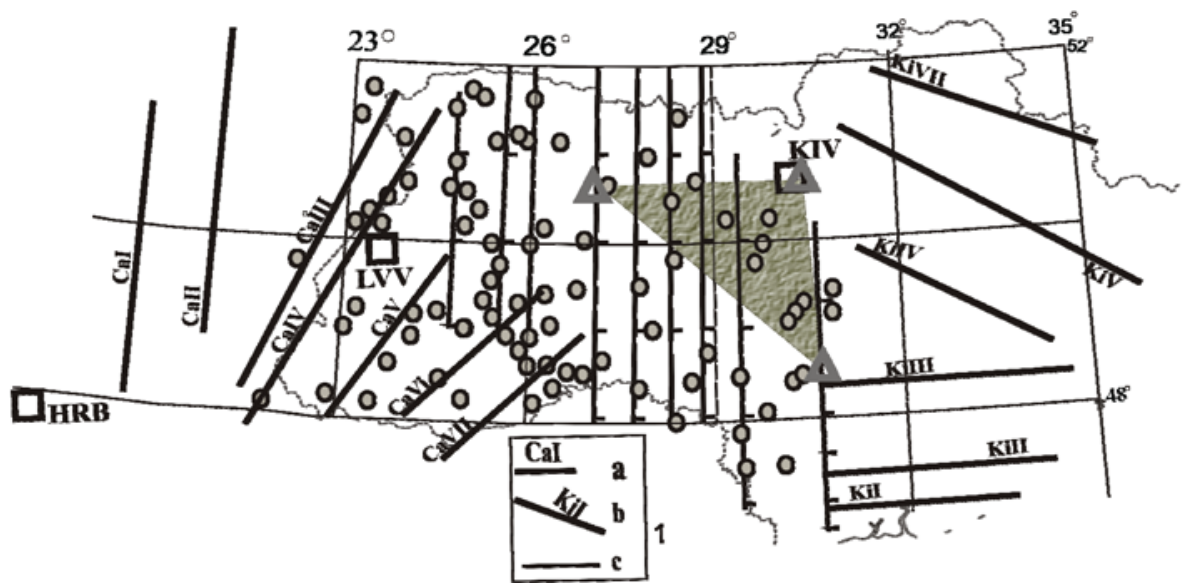

Fig. 2. Locations of sounding sites: a - MT profiles in the Carpathians $(\mathrm{Ca}), \mathrm{b}-\mathrm{MT}$ profiles in the western EEP part (Ki), c - central longitudinal MT profiles; circles DMTS sites; squares - geomagnetic observatories Kiev (KIV), Lviv (LVV), and Hurbanovo (HRB); triangles - three GMVS sites. 
(GMVS) method (Ladanivskyy et al. 2010) fills data gaps in the specified range of periods.

Data processing of the observed variations of magnetotelluric fields was carried out using the usual boundary conditions on the Earth's surface according to the formulae:

$$
\begin{aligned}
& E_{x}(\omega, \mathbf{r})=Z_{x x}(\omega) B_{x}(\omega)+Z_{x y}(\omega) B_{y}(\omega), \\
& E_{y}(\omega, \mathbf{r})=Z_{y x}(\omega) B_{x}(\omega)+Z_{y y}(\omega) B_{y}(\omega), \\
& B_{z}(\omega, \mathbf{r})=W_{z x}(\omega, \mathbf{r}) B_{x}(\omega, \mathbf{r})+W_{z y}(\omega, \mathbf{r}) B_{y}(\omega, \mathbf{r}),
\end{aligned}
$$

where $E(\omega, \mathbf{r})$ and $B(\omega, \mathbf{r})$ are complex Fourier amplitudes of orthogonal horizontal components of the electric $\mathbf{E}(t)$ and magnetic fields $\mathbf{B}(t), \omega$ is the angular frequency, $\mathbf{r}$ is the radius vector on a plane surface of the Earth, $Z(\omega, \mathbf{r})$ is the impedance, and $W_{z}(\omega, \mathbf{r})$ is the the magnetic transfer function. A more complicated theory was suggested by Schmucker (Schmucker 2003) and Shuman (Shuman and Kulik 2002).

Several types of processing algorithms based on the spectral analysis (Egbert and Booker 1986, Egbert 1997, Semenov 1998, Ladanivskyy 2003) and on the analysis of time domain convolution functions (Wielądek and Ernst 1977) were applied to the collected data. Finally, the impedance and magnetic transfer function data were estimated in the period range of 10$10^{4} \mathrm{~s}$. Partly, the processing was carried out using the remote reference method. The impedance polar diagrams analysis allowed the detection of main directions of regional structures. Results of the data processing (apparent resistivity, phases of the impedance, magnetic transfer function) formed the data bank used for the solution of $1 \mathrm{D}, 2 \mathrm{D}$, and quasi-3D modeling and inversion problems.

\section{1D INVERSIONS}

The methodological basis for present inversion studies was elaborated in the frames of the CEMES international project (Semenov et al. 2008). The dense DMTS network allows us to refine the electrical conductivity structure of the crust and mantle on the territory of Ukraine and adjacent narrow strip of Poland. Inverted complex apparent resistivity data were obtained by the extension of DMTS data with regional MVS responses from Ukrainian geomagnetic observatories. The MVS results for the geomagnetic observatory KIV were taken as a reference for EEP sites, while results from observatories LVV and HRB extend data from the Carpathians (Semenov 1998, Semenov and Jóźwiak 2006). Apparent resistivities obtained by different methods displayed a good agreement in phases, while their amplitudes were often distorted by the shift effect. This effect was assumed to be 
frequency independent due to the small conductance level of EEP sediments in Ukraine. Thus, the amplitude curves of DMTS apparent resistivity were shifted to MVS levels before their joint 1D inversions by the OCCAM (Constable et al. 1987) and D+ (Parker and Whaler 1981) methods.

The total conductance $S$ beneath the Ukrainian part of EEP increases slowly and monotonically from the surface to a depth of $\sim 600 \mathrm{~km}$ (the bottom of the upper mantle) and then rapidly from $\sim 30 \mathrm{kS}$ at this depth to $\sim 300 \mathrm{kS}$ at the depth of $800 \mathrm{~km}$ (the center of the mid-mantle). The $S$ error for the upper mantle with sediments is estimated at $20 \%$ level. The main contribution for such a big error comes from the depth interval of 200$400 \mathrm{~km}$, which is the most difficult zone to analyze the Earth's conductivity. This observation is also true for new experimental data giving minimal error bars at the same level (Logvinov 2002). Complex apparent resistivity estimates for Ukrainian sites were recently calculated in this period range using a new approach (Ladanivskyy et al. 2010). No regional conductive layers at depths of $150-500 \mathrm{~km}$ were detected, as distinct from the western TESZ region where the presence of a well-conductive layer at "asthenospheric" depths was found (Jóźwiak 2013).

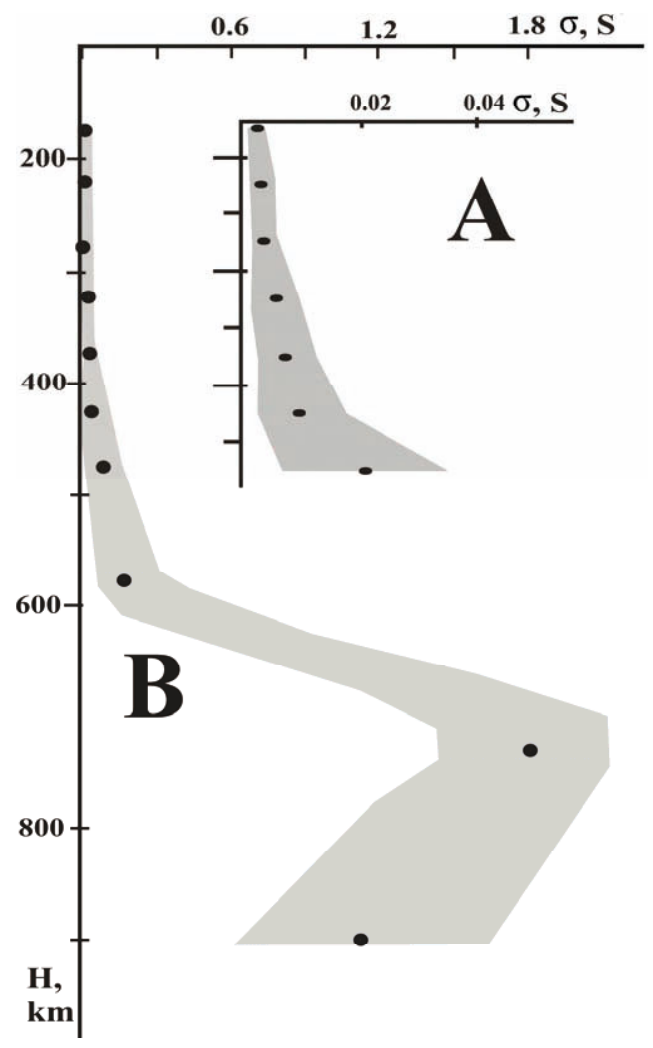

Fig. 3. Averaged conductivity distributions for the southwestern EEP part at depths of $150-500 \mathrm{~km}$ (A) and $150-900 \mathrm{~km}$ (B); bands display mean square errors. 


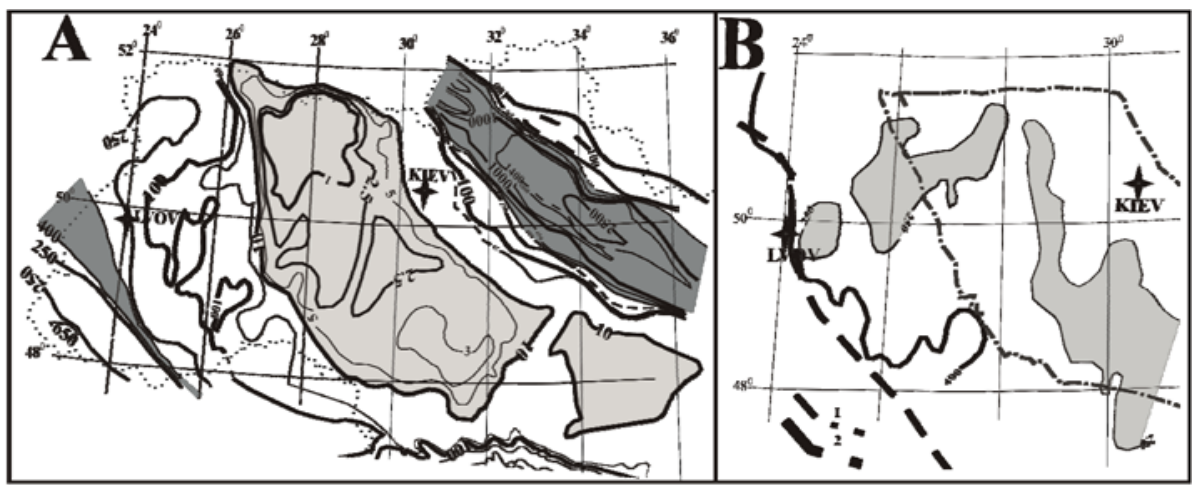

Fig. 4. Conductance maps (in S) for sediments (A) and the crust (B); 1 - the Ukrainian Shield border, 2 - the EEP border.

The averaged conductivity distribution for soundings at 93 sites was estimated from the total conductance $S: \quad \sigma=\operatorname{grad} S$. Conductivity increases slowly and monotonically till the depths of 400-450 km (Fig. 3A) and then sharply at depths greater than $600 \mathrm{~km}$ (Fig. 3B). The maximal conductivity is observed at $\sim 700 \mathrm{~km}$ and a layer with lower conductivity appears at a greater depth of $800-1000 \mathrm{~km}$. A similar distribution of $\operatorname{grad} S$ with depth was obtained for the Polish EEP part (Semenov and Jóźwiak 2005). This result does not contradict with the results obtained previously (Semenov and Jóźwiak 1999).

Two strong crustal conductivity anomalies, namely, the Carpathian and the Kirovograd, are well known in Ukraine. The condition of horizontal medium homogeneity is not true in these areas and therefore the 1D inversion was not used here.

The sedimentary and, partly, crustal conductancies were additionally estimated using both the data obtained from DC resistivity soundings and 1D inversion at $\sim 200$ MT prospecting sites (with the period range of 1-3600 s). The resulting conductance maps for the crust (Logvinov 2012) and sediments (Ingerov et al. 1999, Logvinov 2012) are presented in Fig. 4. The crustal conductance exceeds the level of $250 \mathrm{~S}$ only in areas close to the EEP border (Fig. 4B).

The Moho boundary is situated in the studied region at depths of 40$50 \mathrm{~km}$ according to seismic data (Gordienko et al. 2005, 2012). For the average depth of the crust, the value of $45 \mathrm{~km}$ was accepted.

\section{2D INVERSIONS}

The analysis of experimental data at all the profiles shown in Fig. 2 was made using 2D inversion code REBOCC (Siripunvaraporn and Egbert 
2000). In this study the misfit between modelled and experimental data was considered satisfactory at the levels of 0.1 for magnetic transfer function, $10^{\circ}$ for the impedance phase, and $30 \%$ for the apparent resistivity. The goal of the REBOCC inversion was to find the minimum norm model at these misfit levels. To estimate the integral conductivity of local structures the parameter $G$ (Rokityansky 1982) was used:

$$
G_{i}=Q_{i} / \rho_{i},
$$

where $Q_{i}$ is the cross-section area of the conductive object (in $\mathrm{m}^{2}$ ), and $\rho_{i}$ is its resistivity (in Ohm-m). In case of complex multi-segment structures the overall $G=\sum G_{i}$.

Inversion starting models account for the information known from drilling and seismic surveys, mainly, the thickness of sediments. The "normal" section for the Ukrainian EEP part was based on 1D inversion results obtained at the observatory KIV, while in the Carpathian region the 1D model for the observatory LVV was used (Semenov et al. 2008).

Inverted experimental data included impedance estimates for TM and TE modes and magnetic transfer functions. Data at 10-30 sites and 10-13 periods in the period range of 4-3600 s were selected at different profiles. First calculations were carried out separately for TE, TM impedances, and magnetic transfer functions (named below as TP). At the final inversion stage the model with the smallest RMS for these separate mode solutions was chosen as the starting for the joint $\mathrm{TE}+\mathrm{TM}+\mathrm{TP}$ inversion.

The description of the main features of the Carpathian anomaly of conductivity (CrAC) derived from 2D inversion models for all profiles shown in Fig. 2 (CaI-CaVII) is summarized in Table 1. The comparison of these models with the tectonics of the Carpathians indicates that CrAC is located between the Magura thrust and Pieniny Klippen Belt (Fig. 1). The depth to the top of CrAC decreases to the east of the CaIII profile from 8 to $5 \mathrm{~km}$. The integral CrAC conductivity is reduced in the same direction. The width of this anomaly changes between 33 and $45 \mathrm{~km}$.

The modeling along $\mathrm{CaI}$ and $\mathrm{CaII}$ has revealed a sharp difference in parameters of CrAC in the Tatra Mountains and Eastern Carpathians: the width is reduced at least twice and the depth to its top is increased. The conductance of the anomaly is much smaller in the Tatra Mts (CaI and CaII) than in the Eastern Carpathians (CaIII-CaVII).

The Kirovograd conductivity anomaly (KrAC) is covered with profile soundings on its whole length, from the coast of the Black Sea to the northern border of Ukraine (Fig. 2, KiI-KiVI). Its boundaries correlate with faults forming the Ingulets-Krivoy Rog-Krupetsk suture zone (Fig. 1). The KrAC modelling results can be presented in the form of two separated objects, A 
Table 1

Features of the Carpathian and the Kirovograd conductivity anomalies

\begin{tabular}{|c|c|c|c|c|}
\hline Profiles & $\begin{array}{c}\text { Depth of the top } \\
{[\mathrm{km}]}\end{array}$ & $\begin{array}{c}\text { Width } \\
{[\mathrm{km}]}\end{array}$ & $\begin{array}{r}G \times 10^{7} \\
{[\mathrm{~S} \cdot \mathrm{m}]}\end{array}$ & \multirow{2}{*}{ Note } \\
\hline \multicolumn{5}{|c|}{ Carpathian conductivity anomaly } \\
\hline CaI & 18 & 18 & 7.2 & \\
CaII & 18 & 15 & 8.2 & \\
CaIII & 8 & 33 & 52 & $*$ \\
CaIV & 8 & 45 & 38 & \\
CaV & 7 & 42 & 45 & \\
CaVI & 6 & 33 & 24 & \\
CaVII & 5 & 42 & 14 & \\
\hline \multicolumn{5}{|c|}{ Kirovograd conductivity anomaly } \\
\hline KiI & $28 / 7$ & $18 / 16$ & $5 / 8$ & \\
KiII & $16 / 21$ & $16 / 15$ & $6 / 8.4$ & \multirow{2}{*}{ The numerator } \\
KiIII & $21 / 12$ & $24 / 9$ & $8.3 / 0.3$ & options object A, \\
KiIV & $12 / 10$ & $18 / 5$ & $5 / 0.01$ & denominator - B \\
KiV & $30 / 20$ & $7 / 7$ & $8 / 4.2$ & \\
KiVI & $46 / 15$ & $5 / 10$ & $3 / 0.04$ & \\
\hline
\end{tabular}

${ }^{*}$ For the first time, 2D modelling of modular values of magnetic transition functions (TP) was performed (Zhdanov et al. 1986) along the international Geotraverse II (Fig. 2, CaV). Comparison of the inversion results with the previous model shows good agreement between the geometrical parameters of the two models for the main object, which caused abnormal behavior of TP data along the profile. For example, from the inversion the value of $G$ is $4.5 \times 10^{8} \mathrm{~S} \cdot \mathrm{m}$, while previous value of $G$ is $4.8 \times 10^{8} \mathrm{~S} \cdot \mathrm{m}$. Parameters of the object beneath the Carpathians and the Carpathian Foredeep much differ. According to the inversion results, the main part of the object occurs deeper, and the value of $G$ is 2 times less than in the previous model. The resulting differences are within error limits, as postulated by the authors (Zhdanov et al. 1986).

and B. Table 1 shows their main characteristics at only those profiles which had relatively dense magnetic transfer function estimates, because MT responses were not available at all profiles. Object A has much higher $G$ values than object B.

The joint 2D inversion of TE $+\mathrm{TM}+\mathrm{TP}$ data was carried out along meridian profiles (Fig. 2c) where TE mode corresponds to northern direction of electric field. The inversion models were obtained for data at periods of 16$2500 \mathrm{~s}$. Each profile contained $\sim 20$ observation sites. 2D inversion results 

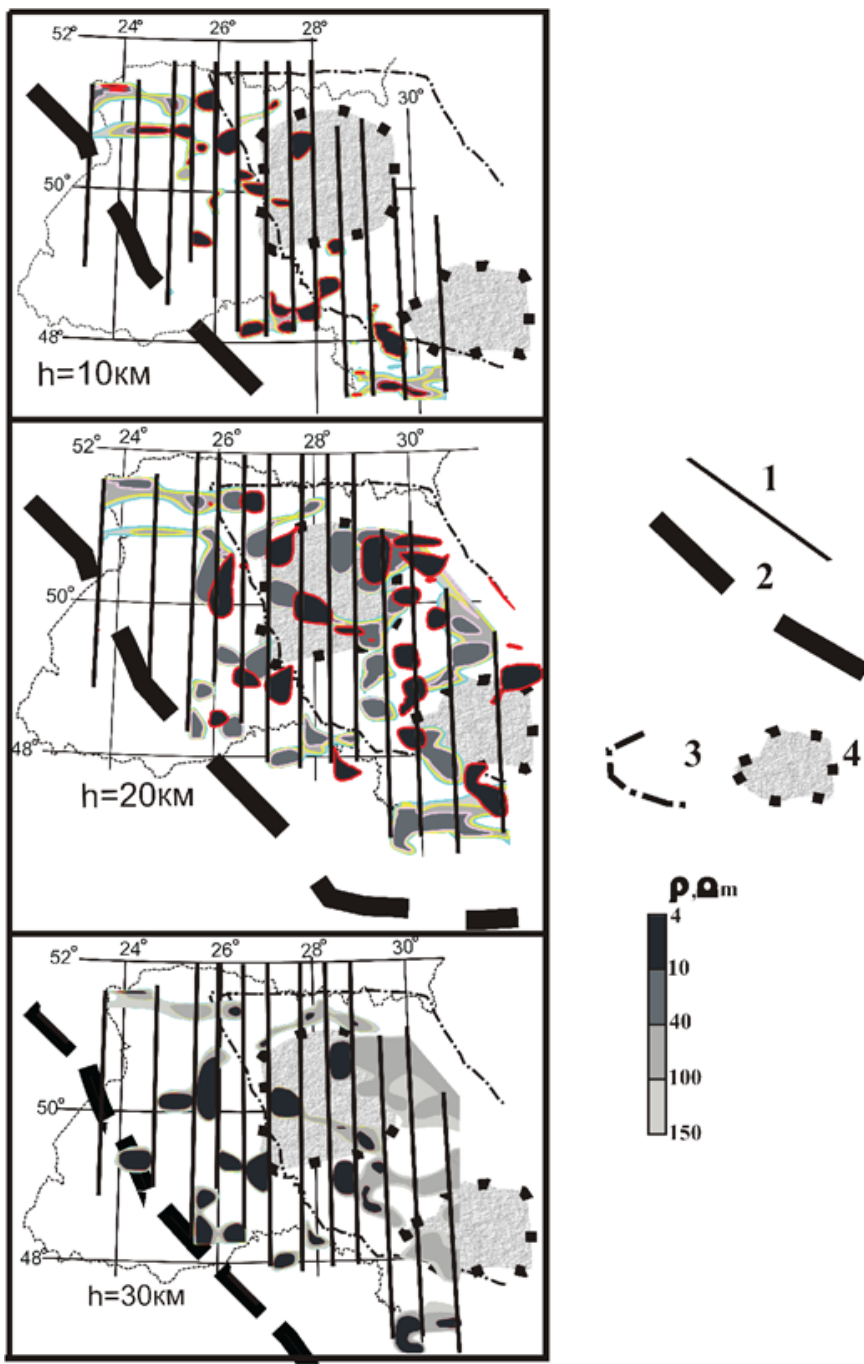

Fig. 5. Contours of crustal conductive objects at the southwestern EEP margin derived from 2D inversion; 1 - inversion profiles, 2 and $3-$ borders of the EEP and the Ukrainian Shield, 4 - graphtization areas (Yatsenko 1996).

show that the investigated area hosts a number of local conductive objects. Top edges of some of them lie in the granite layer, but most of the objects are seen at depth of at least of $20 \mathrm{~km}$ (Fig. 5). Many conductive objects at such a depth are spatially correlated with areas of graphitization (Fig. 5).

\section{QUASI-3D INVERSION}

The models of the Carpathian and the Kirovograd conductivity anomalies obtained from 2D inversion were used as pilot conductivity distributions for a subsequent quasi-3D modelling (Kovacikova 2001). In the thin sheet ap- 
proximation, the anomaly source is replaced by a thin sheet with the anomalous conductance $S$ at a specified depth in the layered normal section. Equivalent currents within the thin sheet are calculated using a Price equation and the magnetic field at the ground surface can be calculated gradually from the related boundary conditions.

The collected magnetic transfer functions $W_{z x}(\omega, \mathbf{r})$ and $W_{z y}(\omega, \mathbf{r})$ for the period range of 400-6000 s at the territory of Czech Republic, Slovakia, Poland, Hungary, and Ukraine made it possible to trace the Carpathian conductivity anomaly (Kovacikova et al. 2010, Gordienko et al. 2011, 2012). The parameters of the layered medium below the sedimentary cover $(>4 \mathrm{~km})$ were taken according to the 1D model for observatory LVV (Semenov et al. 2008). A thin sheet was located at a depth of $10 \mathrm{~km}$ to estimate the conductivity distribution in this layer (Kovacikova et al. 2010). Figure 6 shows the results of such analysis in the Ukrainian Carpathians and the adjacent part of Slovakia.

The magnetic transfer functions for the period range of 40-6000 s were also obtained for the region of the Kirovograd conductivity anomaly (Fig. 6). The complexity in the construction of this quasi-3D model follows from the fact that the anomaly crosses large sedimentary structure of the DnieperDonets Basin (Fig. 6). The sedimentary conductance at depths of 0-2 km was taken according to the data shown in Fig. 4. The parameters of layered medium below the sedimentary cover were taken according to 1D model for

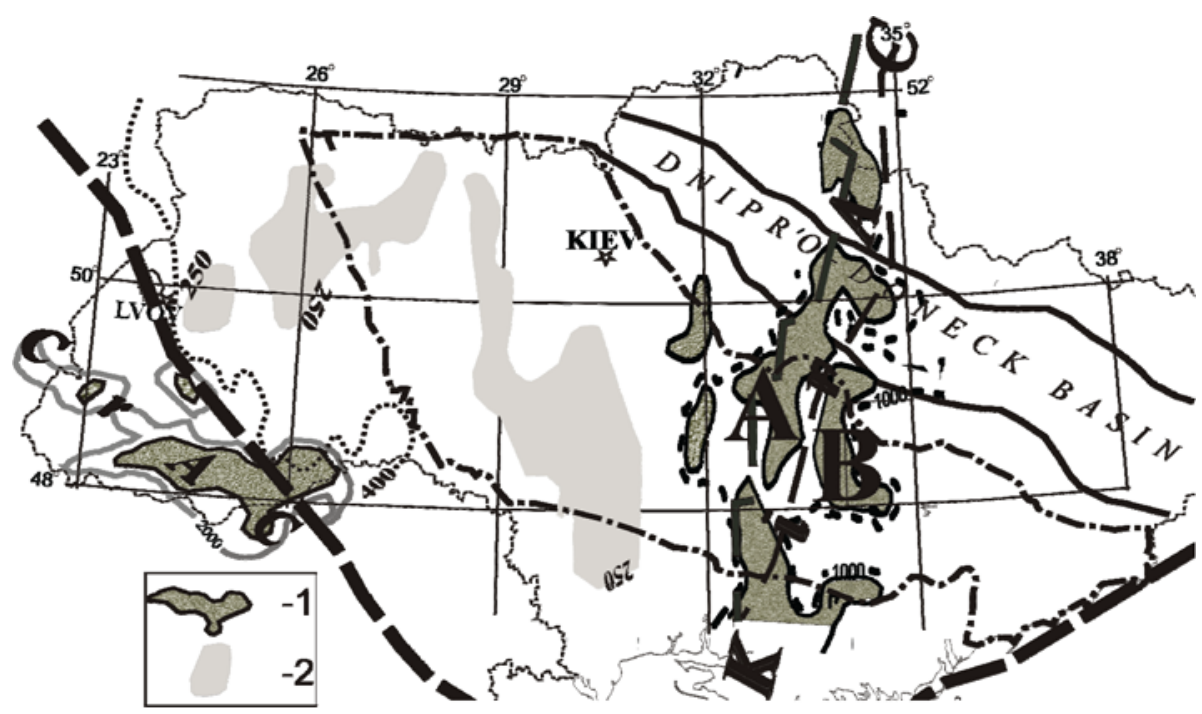

Fig. 6. The crustal conductance in Ukraine according to quasi-3D and 1D inversion of the MTS impedances; conductance values are shown over $4000 \mathrm{~S}$ (1) and less than $250 \mathrm{~S}$ (2); other notations in Fig. 1. 
observatory KIV (Semenov et al. 2008). The thin sheet in the inversion was located at a depth from 12 to $20 \mathrm{~km}$ (Gordienko et al. 2005, 2006).

In recent years the new research has traced the Kirovograd anomaly from Ukraine into SW Russia in the frames of the international project KIROVOGRAD (Varentsov et al. 2012). The detailed description of the results of this project studying the geoelectrical structure of the western slope of the Voronezh Massive in Russia and Ukraine by means of the advanced simultaneous deep EM sounding array with natural field excitation and geological and geophysical analysis of the nature of the revealed crustal conducting anomalies has been given by Varentsov et al. (2012, 2013). Geoelectrical sections along the series of profiles and maps of sedimentary and crustal conductance obtained from $2 \mathrm{D}+$ and quasi-3D data interpretations are shown in the sited papers. The main advantage of these studies was the use of horizontal MV inter-station responses at the stage of quasi-3D inversion with the two-sheet conductance estimation separated for subsurface and deep crustal distributions (Varentsov et al. 2012, 2013).

\section{CONCLUSION AND DISCUSSION}

The distribution of the sedimentary conductance was estimated at for territory of Ukraine and was used to build a world map of the sedimentary conductance (Vozar et al. 2006). These estimates are reaching $1000 \mathrm{~S}$ and more in the deep sedimentary basins only. The crustal conductance is less than $250 \mathrm{~S}$ for most parts of Ukraine. Two regional crustal anomalies exist there, and numerous additional local objects of low resistance were discovered. Most of them do not form large homogeneous areas in Ukraine. The greatest number of such objects is located in the range of $20-30 \mathrm{~km}$ in the Ukrainian Shield.

The obtained characteristics of the geoelectric crustal structure confirm the existence of two regional conductivity anomalies, namely, the Carpathian and the Kirovograd ones (Fig. 6). The modelling showed that the Carpathian conductivity anomaly in the Ukrainian Carpathians is located between the Pieniny Klippen Belt and the Magura thrust zone.

The anomalous behavior of MT fields in the region of Kirovograd conductivity anomaly can be explained by the existence of two conductive objects. These objects appear in 2D inversion, as well as in quasi-3D inversion, and spatially correspond to the location of the boundary fault zones that delineate the Ingulets-Krivoy Rog-Krupetsk suture zone. The strongest anomaly of the integral conductivity of object $\mathrm{A}$ is confined to the western fault zone and is located in the depth range of 18-40 km (Logvinov 2012).

The spatial distribution of the integral conductivity was obtained in Ukraine for the depth interval from the surface to $900 \mathrm{~km}$. The same distribution was obtained at the Polish part of the EEP (Semenov and Jóźwiak 
2005) and in Eurasia (Semenov and Jóźwiak 1999). The most conductive part of the mantle is situated at depths of $600-900 \mathrm{~km}$. Conductivity distribution at the upper mantle depths may be presented as a layer with a gradual increase of conductivity with depth. The distribution of the mantle's apparent resistivity obtained for such a model was chosen as a reference for the correction of shift-effect in the MTS results.

We note that the new data and conclusions about the deep structure of the western part of Ukraine substantially complement the available concepts based primarily on the results of seismic and gravity-magnetic survey.

Acknowledgments. I am thankful to V.Yu. Semenov for simulating the work and for discussions.

\section{References}

Ádám, A., T. Ernst, J. Jankowski, W. Jóźwiak, M. Hvozdara, L. Szarka, V. Wesztergom, I. Logvinov, and S. Kulik (1997), Electromagnetic induction profile (PREPAN95) from the East European Platform (EEP) to the Pannonian Basin, Acta Geod. Geophys. Hung. 32, 1-2, 203-223, DOI: 10.1007/ BF03325488.

Bondarenko, A.P., A.I. Bilinsky, and F.I. Sedova (1972), Geoelectromagnetic Variations in the Soviet Carpathians, Naukova Dumka, Kiev, 116 pp. (in Russian).

Constable, S.C., R.L. Parker, and C.G. Constable (1987), Occam's inversion: A practical algorithm for generating smooth models from electromagnetic sounding data, Geophysics 52, 3, 289-300, DOI: 10.1190/1.1442303.

Dyakonova, A.G., A.I. Ingerov, and I.I. Rokityansky (1986), Electromagnetic Soundings on the Eastern European Platform and in the Ural, Naukova Dumka, Kiev (in Russian).

Egbert, G.D. (1997), Robust multiple-station magnetotelluric data processing, Geophys. J. Int. 130, 2, 475-496, DOI: 10.1111/j.1365-246X.1997.tb05663.x.

Egbert, G.D., and J.R. Booker (1986), Robust estimation of geomagnetic transfer functions, Geophys. J. Int. 87, 1, 173-194, DOI: 10.1111/j.1365-246X. 1986.tb04552.x.

Gordienko, V.V., I.V. Gordienko, O.V. Zavgorodnyaya, S. Kovachikova, I.M. Logvinov, V.N. Tarasov, and O.V. Usenko (2005), Ukrainian Shield (Geophysics, Deep Processes), Korvin Press, Kiev (in Russian).

Gordienko, V.V., I.V. Gordienko, O.V. Zavgorodnyaya, S. Kovachikova, I.M. Logvinov, J. Pek, V.N. Tarasov, and O.V. Usenko (2006), Dnepr-Doneck Basin (Geophysics, Deep Processes), Korvin Press, Kiev, 143 pp. (in Russian). 
Gordienko, V.V., I.V. Gordienko, O.V. Zavgorodnyaya, S. Kovachikova, I.M. Logvinov, V.N. Tarasov, and O.V. Usenko (2011), Ukrainian Carpathians (Geophysics, Deep Processes), Logos, Kiev (in Russian).

Gordienko, V.V., I.V. Gordienko, O.V. Zavgorodnyaya, S. Kovachikova, I.M. Logvinov, and V.N. Tarasov (2012), Volyno-Podolian Plate (Geophysics, Deep Processes), Naukova Dumka, Kiev (in Russian).

Ingerov, A.I., I.I. Rokityansky, and V.I. Tregubenko (1999), Forty years of MTS studies in the Ukraine, Earth Planets Space 51, 10, 1127-1133, DOI: 10.1186/BF03351586.

Jankowski, J., J. Marianiuk, A. Ruta, C. Sucksdorff, and M. Kivinen (1984), Longterm stability of a torgue-balance variometer with photoelectric converters in observatory practice, Geophys. Surv. 6, 3-4, 367-380, DOI: 10.1007/97894-009-5283-6_17.

Jóźwiak, W. (2013), Electromagnetic study of lithospheric structure in the marginal zone of East European Craton in NW Poland, Acta Geophys. 61, 5, 11011129, DOI: 10.2478/s11600-013-0127-z.

Kovacikova, S. (2001), Modelling of the geomagnetic induction anomaly sources over the eastern margin of the Bohemian Massif and its contact with the West Carpathians, Ph.D. Thesis, Univerzita Karlova, Praha, Czech Republic, $95 \mathrm{pp}$.

Kovacikova, S., W. Jóźwiak, I. Logvinov, K. Nowożyński, J. Pek, B. Ladanivskyy, and V. Tarasov (2010), Database of geomagnetic induction vectors across the Carpathians and modelling of the regional conductivity distribution. In: 19th Congress of the Carpathian-Balkan Geological Association, 23-26 September, Thessaloniki, Greece.

Ladanivskyy, B.T. (2003), The algorithm of data processing MTS. In: Abstracts Fifth Geophysical Readings of V.V. Fedinskogo, 27 February - 1 March 2003, Moscow, Russia, 134-135 (in Russian).

Ladanivskyy, B.T., V.Yu. Semenov, and I.M. Logvinov (2010), Magnetovariational sounding method of Earth's mantle at period band $10^{4}-10^{5} \mathrm{~s}$, Geophys. J. 32, 3, 50-59 (in Russian).

Logvinov, I.M. (2002), Applying the horizontal spatial gradient method for the deep conductivity estimations in the Ukraine, Acta Geophys. Pol. 50, 4, 567-573.

Logvinov, I.M. (2012), Geoelectrical parameters of the crust and mantle south-west of the East-European platform and Carpathians, Ph.D. Thesis, Subbotin Institute of Geophysics, National Academy of Sciences of Ukraine, Kiev, Ukraine, 306 pp. (in Russian).

Parker, R.L., and K.A.Whaler (1981), Numerical methods for establishing solutions to the inverse problem of electromagnetic induction, J. Geophys. Res. 86, B10, 9574-9584, DOI: 10.1029/JB086iB10p09574.

Rakhlin, L., L. Guleuk, E. Nakalov, and O. Kuznecov (2005), Magnetotelluric station GEOMAG-02. In: New Geophysical Technology Forecasting and Monitoring of the Geological Environment, Lviv, 22-23 (in Russian). 
Rokityansky, I.I. (1982), Geoelectromagnetic Investigation of the Earth's Crust and Mantle, Springer Verlag, Berlin Heidelberg, DOI: 10.1007/978-3-64261801-7.

Rokityansky, I.I., S.N. Kulik, I.M. Logvinov, and V.N. Shuman (1976), Deep magnetovariational studies in Ukraine. In: A. Ádám (ed.), Geoelectric and Geothermal Studies, KAPG Geophysical Monograph, Hungarian Academy of Sciences, Budapest, 634-639.

Schmucker, U. (2003), Horizontal spatial gradient sounding and geomagnetic depth sounding in the period range of daily variations. In: Protokoll uber das 20. Kolloquium Elektromagnetische Tiefenforschung, 29.09-3.10.2003, Königstein, Germany, 228-237.

Semenov, V.Yu. (1998), Regional conductivity structures of the Earth's mantle, Publs. Inst. Geophys. Pol. Acad. Sc. C-65, 302, 122 pp.

Semenov, V.Yu., and W. Jóźwiak (1999), Model of the geoelectrical structure of the mid- and lower mantle in the Europe - Asia region, Geophys. J. Int. 138, 2, 549-552, DOI: 10.1046/j.1365-246X.1999.00888.x.

Semenov, V.Yu., and W. Jóźwiak (2005), Estimation of the upper mantle electric conductance at the Polish Margin of the East European Platform, Izv. Phys. Solid Earth 41, 4, 326-332.

Semenov, V.Yu., and W. Jóźwiak (2006), Lateral variations of the mid-mantle conductance beneath Europe, Tectonophysics 416, 1-4, 279-288, DOI: 10.1016/ j.tecto.2005.11.017.

Semenov, V.Yu., S.N. Kulik, and I.M. Logvinov (1998), Estimations of the geoelectrical structure of the mantle in Ukraine, Dokl. Nat. Acad. Sc. 10, 134-137.

Semenov, V.Yu., J. Pek, A. Ádám, W. Jóźwiak, B. Ladanyvskyy, I.M. Logvinov, P. Pushkarev, J. Vozar, and Experimental Team of CEMES Project (2008), Electrical structure of the upper mantle beneath Central Europe: Results of the CEMES project, Acta Geophys. 56, 4, 957-981, DOI: 10.2478/s11600008-0058-2.

Shuman, V., and S. Kulik (2002), The fundamental relations of impedance type in general theories of the electromagnetic induction studies, Acta Geophys. Pol. 50, 4, 607-618.

Siripunvaraporn, W., and G. Egbert (2000), An efficient data-subspace inversion method for 2-D magnetotelluric data, Geophysics. 65, 3, 791-803, DOI: 10.1190/1.1444778.

Varentsov, Iv.M., S. Kovacikova, V.A. Kulikov, I.M. Logvinov, V.I. Tregubenko, A.G. Yakovlev, and Workgroup KIROVOGRAD (2012), Simultaneous magnetotelluric and magnetovariational soundings in the western slope Voronezh massif, Geophys. J. 34, 4, 90-107 (in Russian).

Varentsov, I.M., V.V. Gordienko, I.V. Gordienko, O.V. Zavgorodnyaya, S. Kovachikova, I.M. Logvinov, V.N. Tarasov, and V.I. Tregubenko (2013), The Slope of the Voronezh Crystalline Massif (Geophysics, Deep processes), Logos, Kiev (in Russian). 
Vozar, J., V.Yu. Semenov, A.V. Kuvshinov, and C. Manoj (2006), Updating the map of Earth's surface conductance, Eos Trans. AGU 87, 33, 326-331, DOI: $10.1029 / 2006 \mathrm{EO} / 33004$.

Wielądek, R., and T. Ernst (1977), Application of the method of least squares to determining impulse responses and transfer functions, Publs. Inst. Geophys. Pol. Acad. Sc. G-1, 110.

Yatsenko, V.G. (1996), Structural and morphological and genetic types of graphite on an example of deposits of the Ukrainian shield, Ph.D. Thesis, Institute of Geology, Academy of Sciences of Ukraine, Kiev, Ukraine, 253 pp. (in Russian).

Zhdanov, M.S., N.G. Golubev, I.M. Varentsov, L.M. Abramova, V.S. Shneer, M.N. Berdichevsky, O.N. Zhdanova, V.V. Gordienko, S.N. Kulik, and A.I. Bilinsky (1986), 2-D model fitting of a geomagnetic anomaly in the Soviet Carpathians, Ann. Geophys. B 4, 3, 335-342.

Received 28 January 2014 Received in revised form 3 November 2014

Accepted 18 November 2014 